\title{
European initiative to provide Africa with control of therapeutic development
}

Africa-led partnership with the European Union hopes to accelerate clinical development of HIV, tuberculosis and malaria treatments.

\section{Tom Clarke}

The European Commission is inviting applications for an ambitious new funding scheme designed to put Africans in control of developing treatments for HIV/AIDS, tuberculosis and malaria in the continent.

African health ministers are yet to be convinced: well-meaning and well-financed donors come and go, yet drug and vaccine regimens for their nation's poor people are yet to appear.

But the Europe-Developing Countries Clinical Trials Partnership (EDCTP) is different, say its backers. Built upon bitter previous experience of aid agencies or drug companies' failure to conduct safe, ethical or relevant drug and vaccine trials in developing countries - especially Africa - it will not make the same mistakes.

Partnership, says Philippe Busquin, the head of research at the European Union's executive body, the European Commission (EC), is the key word. "Research into treatments doesn't just mean working in laboratories, it also means working with victims in their own communities," he says.

Previous trials have failed due to inadequate follow-up of trial participants, along with poor clinical practice and data collection. Issues of consent in countries with sexual inequality and low levels of literacy make ethical elements of trials established in developed countries difficult to transfer.

It is also essential that drugs and vaccines are developed in these countries, rather than shipped in. The effectiveness of a malaria vaccine can only be assessed in an area where the disease is endemic, and among people who have a certain amount of natural immunity to the disease. HIV drugs and vaccines must be shown to be effective against the different viral subtypes and varying modes of transmission found in different parts of the world.

The initiative has unprecedented financial and political support from Europe. The EC is giving $€ 200$ million (US $\$ 200$ million) over five years, with $€ 200$ million more coming from EC member states. Industry partners, or private foundations, are expected to contribute a similar amount.

Applications for funding are still being invited, but sites that Busquin visited recently in east Africa epitomize the

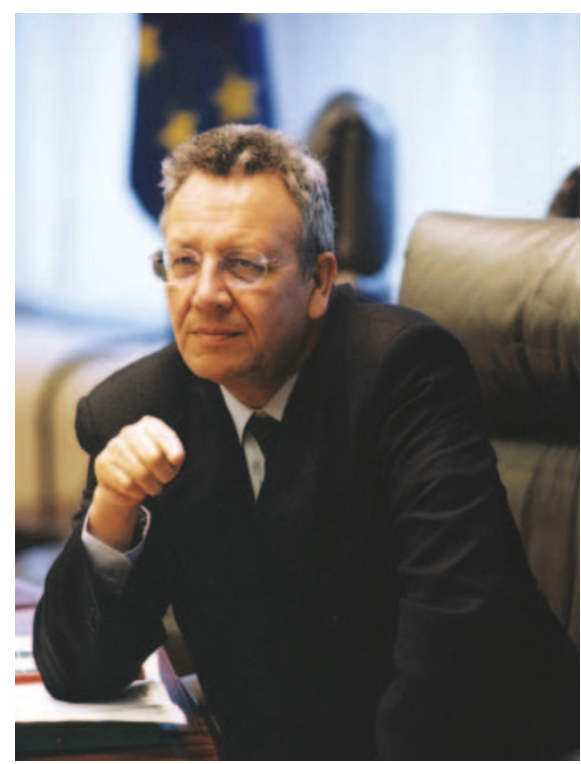

Philippe Busquin, Commissioner for Research at the European Commission. Photo courtesy of the European Commission.

cooperation that the initiative is looking to fund. Busquin stresses that projects to be funded must have the backing of the relevant country and the Developing Countries Coordinating Committee - a panel of African and European health experts assembled by the EC.

At Mbeya Regional Medical Centre in Mbeya, Tanzania, researchers from the University of Munich have been studying the dynamics of HIV transmission for more than a decade. Having developed close ties with the regional health commission and community groups, they have been following a cohort of 600 high-risk sex workers and a similar number of not-at-risk people. Registrants in their study are provided with photo ID and free medical treatment, health advice and compensation in return for their cooperation. The Mbeya team is about to embark on a trial of antiretroviral drugs in the community.

At the Manhiça Health Research Centre in rural Mozambique, researchers from the University of Barcelona are mapping the population in the surrounding area. Basic infrastructure, like systems of place names and addresses, is lacking in many of the poorer parts of Africa, especially those, like Mozambique, that were or continue to be shattered by civil war. Visitors to the
Manhiça clinic are given ID cards outlining who they are and where they live. The system has developed as part of the researchers' work on antimalaria interventions and mother-to-child HIV transmission. The site is now the home of GlaxoSmithKline's Phase II paediatric vaccine trial for malaria.

Detailed groundwork such as this means both centres now have the capacity to recruit trial participants, and to identify and reidentify them as any trial progresses. A level of trust between local authorities, institutions and residents further ensures more reliable follow-up and that proper consent is obtained.

The aim of the EDCTP is to develop five such sites suitable for testing drugs for the big three diseases in different parts of Africa. In Manhiça and Mbeya, the infrastructure is pretty much in place. The first round of EDCTP funding, however, will focus on infrastructure development and the training of African doctors and scientists probably through exchanges with partner countries - to carry out trials.

EDCTP has the broad approval of African health experts, notably for its African-led approach. "Usually with aid, the recipe has already been made," says epidemiologist Ricardo Thompson, with the National Institute of Health in Maputo, Mozambique.

The programme has international appeal too. A recent article in Science (Klausner, R. D. et al. Science 300, 2036-2039 (2003)), authored by some of the biggest names in HIV vaccine research, identified the EDCTP concept as the only approach likely to produce a working HIV vaccine for the developing world. The paper also pointed out that around ten times as many similar initiatives would be needed.

"On paper it's an excellent idea," says Robert Ridley, coordinator of product research and development at the United Nation's Special Program for Research and Training in Tropical Diseases. "But African leaders have seen these things come and go," he says. "There's a certain element of 'so show me the money."

With the backing of African health experts the programme is likely to take off, says Thompson, but not without serious commitment: "Now the responsibility lies with us. If this approach fails, it's Africa that has failed." 